research support from: Actelion Pharmaceuticals US, Bayer AG, Bristol-Myers Squibb, Inventiva, Medac, Pfizer Inc, Roche Pharmaceuticals, Genentech and Biogen IDEC Inc. Sanofi-Aventis Pharmaceutical, Servier, Consultant for: Actelion Pharmaceuticals US, Bayer AG, Bristol-Myers Squibb, Inventiva, Medac, Pfizer Inc, Roche Pharmaceuticals, Genentech and Biogen IDEC Inc., SanofiAventis Pharmaceutical, M. Matucci-Cerinic Grant/research support from: Pfizer, Bristol-Myers Squibb, Actelion, UCB Pharma, Consultant for: Actelion, Bayer, ChemomAb, Genentech/Roche, Inventiva, Lilly, Pfizer, J. Pope Grant/research support from: Actelion, Bayer AG, Bristol-Myers Squibb, Merck, Pfizer Inc, Roche, Consultant for: Actelion, Bayer AG, Bristol-Myers Squibb, Merck, Pfizer Inc, Roche, C. Denton Consultant for: Actelion Pharmaceuticals US, Bayer AG, GlaxoSmithKline, CSL Behring, Merck-Serono, Roche Pharmaceuticals, Genentech and Biogen IDEC Inc., Inventiva, Sanofi-Aventis Pharmaceutical, Boehringer Ingelheim, Speakers bureau: Actelion Pharmaceuticals US, Bayer AG, GlaxoSmithKline, CSL Behring, Merck-Serono, Roche Pharmaceuticals, Genentech and Biogen IDEC Inc., Inventiva, Sanofi-Aventis Pharmaceutical, Boehringer Ingelheim, D. Khanna Shareholder of: Eicos, Grant/research support from: Bayer, Bristol-Myers Squibb, Boehringer Ingelheim, Genentech/Roche, NIH, Pfizer, SanofiAventis Pharmaceuticals, Consultant for: Actelion Pharmaceuticals US, Bayer, Bristol-Myers Squibb, Boehringer Ingelheim, Chemomab, Corbus, Covis, Cytori, Eicos, EMD Serono, Genentech/Roche, Pfizer, Gilead, GlaxoSmithKline, SanofiAventis Pharmaceuticals, and UCB Pharma, O. Distler Grant/research support from: Actelion, Bayer, Biogen Idec, Boehringer Ingelheim, ChemomAb, EspeRare Foundation, Genentech/Roche, GlaxoSmithKline, Inventiva, Lilly, Medac, Medlmmune, Mitsubishi Tanabe Pharma, Pharmacyclics, Novartis, Pfizer, Sanofi, Sinoxa, and UCB in the area of potential treatments of scleroderma and its complications. Patent mir-29 for the treatment of systemic sclerosis licensed, Consultant for: Actelion, Bayer, Biogen Idec, Boehringer Ingelheim, ChemomAb, EspeRare Foundation, Genentech/Roche, GlaxoSmithKline, Inventiva, Lilly, Medac, Medlmmune, Mitsubishi Tanabe Pharma, Pharmacyclics, Novartis, Pfizer, Sanofi, Sinoxa, and UCB in the area of potential treatments of scleroderma and its complications.

DOI: 10.1136/annrheumdis-2018-eular.5248

\section{SAT0514 MRI - GUIDED THERAPY FOR SYSTEMIC SCLEROSIS ASSOCIATED MYOSITIS}

Y. Braun-Moscovici ${ }^{1}$, D. Militianu ${ }^{2}$, N. Puchkov ${ }^{2}$, D. Markovits ${ }^{1}$, M. Braun ${ }^{3}$, M. A. Nahir ${ }^{1}$, A. Balbir-Gurman ${ }^{1} .{ }^{1}$ Rheumatology department, Rambam Health Care Campus, Rappaport Faculty of Medicine, Technion; ${ }^{2}$ Department of Medical Imaging, Rambam Health Care Campus, Rappaport Faculty of Medicine, Technion, Haifa; ${ }^{3}$ Liver Institute, Beilinson Hospital, Sackler School of Medicine, Tel Aviv University, Petach Tikva, Israe

Background: Muscle involvement in systemic sclerosis (SSc) has a significant impact on morbidity, functional capacity, and mortality. The muscle histopathology is heterogeneous including inflammatory and fibrotic changes. Currently there are no satisfactory means to diagnose inflammatory myopathy in SSc pts with normal creatine kinase (CK) and to assess the response to therapy.

Objectives: Our aim was to evaluate whether muscle magnetic resonance imaging (MRI) might be a tool to diagnose inflammatory myopathy in SSc patients (pts) and to assess the effect of muscle oriented-immunomodulatory therapy.

Methods: We retrospectively analysed the clinical data of 290 consecutive SSc pts seen at our centre between the years 2012-2017. Our cohort is part of the EUSTAR registry (centre 042). Pts with muscle weakness as defined by the Medsger muscle severity score of $>1$ and at least one MRI study were included. Clinical data analyzis included SSc subtype, disease duration, modified Rodnan skin score (mRSS), Medsger muscle severity score, CK, autoantibody profile, $\mathrm{MRI}$ and immunomodulatory treatment.

Results: 26 pts with muscle weakness answered the criteria of Medsger muscle severity score of $\geq 1 \mathrm{MRI}$ data were available, in 17 of the pts. Muscle oedema and fasciitis were seen in MRI in 13 pts (10 diffuse subset, median: age 40, disease duration 1.25 years, mRSS 13.5). MRI was normal in 4 pts (2diffuse SSc, median: age 50 years, disease duration 6 years, mRSS 4). CK was normal in 10 pts with pathologic MRI. Anti-topoisomerase was positive in 6 pts, RNA polymerase 3 - in 3 pts, anti-centromere - in 2 pts and 6 pts were only ANA positive. Muscle biopsy results were available in 4 pts: Biopsy was compatible with myositis in 3 pts with pathologic MRI and revealed fibrosis in 1 pt with normal MRI. 14 pts received immunomodulatory treatment: rituximab (3 pts), rituximab and intravenous immunoglobulins (IVIG) (3 pts), IVIG and methotrexate/azathioprine/mycophenolate mofetil. ${ }^{8} \mathrm{~A}$ second MRI was performed in 6 pts with first pathologic MRI, after 12 months of treatment. Significant regression of muscle oedema and perifasciitis was observed in 5 pts and correlated with clinical amelioration, with improvement of muscle strength. No clinical and imaging improvement occurred in one patient, despite the treatment. No change in muscle strength was seen in the patient with normal MRI and evidence of fibrosis on muscle biopsy, although the skin score improved.
Conclusions: MRI might serve as a non-invasive tool for diagnosis of inflammatory myopathy in SSc pts with early disease, Medsger muscle severity score of $\geq 1$ and normal CK and for assessment of treatment efficacy.

Disclosure of Interest: None declared

DOI: 10.1136/annrheumdis-2018-eular.6511

\section{SAT0515 CLINICAL CHARACTERISTICS OF PATIENTS WITH CANCER-ASSOCIATED MYOSITIS COMPLICATED BY INTERSTITIAL LUNG DISEASE}

Y. Kaneko $^{1}$, T. Nunokawa ${ }^{2}$, Y. Taniguchi ${ }^{3}$, Y. Yamaguchi ${ }^{4}$, T. Gono ${ }^{5}$, K. Masui ${ }^{6}$, A. Kawakami ${ }^{7}$, Y. Kawaguchi ${ }^{8}$, S. Sato ${ }^{9}$, M. Kuwana ${ }^{5}$ on behalf of JAMI investigators. ${ }^{1}$ Division of Rheumatology, Department of Internal Medicine, Keio University School of Medicine; ${ }^{2}$ Department of Rheumatic Diseases, Tokyo Metropolitan Tama Medical Center, Tokyo; ${ }^{3}$ Department of Endocrinology, Metabolism, Nephrology and Rheumatology, Kochi Medical School Hospital, Kochi; ${ }^{4}$ Department of Environmental Immuno-Dermatology, Yokohama City University Graduate School of Medicine, Kanagawa; ${ }^{5}$ Department of Allergy and Rheumatology, Nippon Medical School Graduate School of Medicine, Tokyo; ${ }^{6}$ Department of Anesthesiology, National Defense Medical College School of Medicine, Saitama; ${ }^{7}$ Department of Immunology and Rheumatology, Nagasaki University Graduate School of Biomedical Sciences, Nagasaki; ${ }^{8}$ Institute of Rheumatology, Tokyo Women's Medical University, Tokyo; ${ }^{9}$ Division of Rheumatology, Department of Internal Medicine, Tokai University School of Medicine, Kanagawa, Japan

Background: Cancer-associated myositis (CAM) is believed to be rarely complicated by interstitial lung disease (ILD), and, thus, detailed clinical characteristics of CAM in patients with polymyositis (PM)/dermatomyositis (DM)-associated ILD are not well known

Objectives: To clarify the incidence, risk factors, and impact on survival of malignancy in patients with $\mathrm{PM} / \mathrm{DM}$-associated ILD, using a large cohort data.

Methods: We used 497 patients with PM/DM-associated ILD enrolled in a multicentre retrospective cohort of incident cases from 44 institutions across Japan (JAMI). CAM was defined as malignancy diagnosed within 3 years before or after PM/DM diagnosis. Demographic data and clinical characteristics were recorded at the time of diagnosis, and follow-up survival and malignancy data were collected prospectively.

Results: Thirty-two patients with CAM (6.4\%) were identified. Patients in the CAM group were older (64.3 vs 55.1 years, $p<0.001$ ), had shorter disease duration at onset (4.1 vs 7.0 months, $p=0.01$ ), and presented with arthritis less frequently $(24.1$ vs $48.5 \%, p=0.01$ ), in comparison with those with non-CAM group. All patients with CAM were older than 40 years, and the proportion of CAM increased along with the age. Patients who were $\geq 59$ years at diagnosis and lacked arthritis were at 12 times higher risk for concomitant malignancy than those without such features (figure 1). Frequencies of autoantibodies, including antiMDA5, anti-ARS, and anti-TIF1gamma, were not different between the groups. In 19 patients $(59 \%)$, malignancy was diagnosed within 3 months before or after $\mathrm{PM} /$ DM diagnosis. Eleven CAM patients were died, and cause of deaths included ILD in 6 and malignancy in 5. Survival analysis by Kaplan-Miere method demonstrated that CAM patients had a poorer survival than did non-CAM patients $(p=0.016)$

Conclusions: In patients with PM/DM-associated ILD, older age at diagnosis and lack of arthritis are predictors for concomitant malignancy, which leads to a reduced survival.

Disclosure of Interest: Y. Kaneko Speakers bureau: Astellas, T. Nunokawa: None declared, Y. Taniguchi: None declared, Y. Yamaguchi: None declared, T. Gono: None declared, K. Masui: None declared, A. Kawakami: None declared, Y. Kawaguchi: None declared, S. Sato Grant/research support from: a patent on anti-MDA5 antibody-measuring kit, M. Kuwana Grant/research support from: Astellas, Speakers bureau: Astellas, Japan Blood Products Organisation, Medical and Biological Laboratories

DOI: 10.1136/annrheumdis-2018-eular.3601

\section{SATURDAY, 16 JUNE 2018}

\section{Vasculitis}

\section{SAT0516 TWO DISTINCT SUBSETS OF LOW DENSITY GRANULOCYTES IN ANCA ASSOCIATED VASCULITIS}

A. Endo, Y. Komagata, K. Yamagishi, N. Ikegaya, K. Fukuoka, M. Karube, Y. Arimura, S. Kaname. Division of Nephrology and Rheumatology, First Department of Internal Medicine, Kyorin University School of Medicine, Tokyo, Japan

Background: Low density granulocyte (LDG), a proinflammatory population of neutrophils, was first described in systemic lupus erythematosus (SLE) and has 
been shown to contribute to lupus pathogenesis. It has been suggested that LDGs have a pathogenic role in ANCA associated vasculitis (AAV) based on the data of gene expression signature in AAV and the ability of excessive neutrophil extracellular traps (NETs) formation by LDGs in AAV. However, more detailed analysis of $L D G$ in AAV patients has not been reported.

Objectives: In this study we investigated the characteristics of LDG in AAV patients using flow cytometry and proteomics approach and examined the correlations with disease activity.

Methods: We examined the presence of LDGs in peripheral blood of 10 AAV patients before treatment and followed them for 4 months with immunosuppressive therapy. Normal-density granulocytes (NDGs) were isolated by dextran sedimentation and PBMCs were isolated by Ficoll gradient. LDGs were assessed using cell surface expression of CD14 and CD15 by flow cytometry and isolated by magnetic bead procedure from PBMCs. We performed comparative proteomic analysis among LDGs and autologous NDGs and healthy controls (HC)-NDGs.

Results: LDG frequencies were 9.8-fold higher in AAV patients before treatment relative to $\mathrm{HC}$. There were two distinct populations of LDGs showing different cell surface expressions of CD10, CD14, and CD15 in AAV patients. One population of LDGs was mainly CD10 positive and another one was CD10 negative. Although the frequency of CD10 positive-LDG decreased along with decrease of disease activity, the frequency of CD10 negative-LDG increased in 4 months (17.9-fold higher than before treatment). Comparative proteomic analysis revealed these two populations of LDGs were distinct from each other and had common differences from autologous NDGs and HC-NDGs.

LDG frequencies were 9.8-fold higher in AAV patients before treatment relative to $\mathrm{HC}$. There were two distinct populations of LDGs showing different cell surface expressions of CD10, CD14, and CD15 in AAV patients. One population of LDGs was mainly CD10 positive and another one was CD10 negative. Although the frequency of CD10 positive-LDG decreased along with decrease of disease activity, the frequency of CD10 negative-LDG increased in 4 months (17.9-fold higher than before treatment). Comparative proteomic analysis revealed these two populations of LDGs were distinct from each other and had common differences from autologous NDGs and HC-NDGs.

Conclusions: We identified two distinct subsets of LDGs in AAV. It is possible that they play different roles in the pathogenesis of AAV.

\section{REFERENCES:}

[1] Denny MF, et al. A distinct subset of proinflammatory neutrophils isolated from patients with systemic lupus erythematosus induces vascular damage and synthesizes type I Interferons. J Immunol 2010;184(6):3284-3297.

[2] Grayson, et al. Neutrophil-Related Gene Expression And Low-Density Granulocytes Associated with Disease Activity and Response to Treatment in ANCA-Associated Vasculitis. Arthritis Rheumatol 2015;67:1922-1932.

Disclosure of Interest: None declared

DOI: 10.1136/annrheumdis-2018-eular.3157

\section{SAT0517 GENDER DIFFERENCES INFLUENCES CLINICAL PRESENTATION AND VASCULAR PATTERN IN PATIENTS WITH TAKAYASU ARTERITIS: AN ITALIAN MONOCENTRIC STUDY}

A. Tomelleri, C. Campochiaro, S. Sartorelli, A. Cariddi, G. Cavalli, E. Baldissera, L. Dagna. Unit of Rheumatology, Immunology, Allergy and Rare Diseases (UnIRAR), San Raffaele Scientific Institute, Milan, Italy

Background: Takayasu arteritis(TA) is a large-vessel vasculitis affecting aorta and its major branches ${ }^{1}$. Vascular inflammation may cause luminal narrowing, occlusion or aneurysms ${ }^{2}$. TA affects more frequently young women, but occurrence in patients $>40$ years is not rare. Female:male ratio is $9: 1^{3}$

Objectives: To compare age at disease onset, age at diagnosis and diagnostic delay between male and female Italian TA patients from our cohort. To compare symptoms presentation and vascular involvement

Methods: Data from 10 male and 104 female TA patients (fulfilling ACR criteria) from our tertiary centre were retrospectively collected. Age at diagnosis, age at first symptom onset, diagnostic delay, signs and symptoms subsequently attributed to TA, and arteries involved before the diagnosis were compared. Non-parametric statistic tests were used

Results: In male patients mean age at diagnosis was $33.5 \pm 14.64$ years and mean age at onset was $25.8 \pm 13.01$ years. In female patients mean age at diagnosis was $36.26 \pm 12.6$ years and mean age at onset was $31 \pm 13.1$ years. The differences not being statistically significant. The highest percentage of male patients disease onset was $<18$ years $(40 \%)$, in female patients it was between 18-40 years $(61.5 \%)$. Mean diagnostic delay was $92.9 \pm 80.78$ months in male and 63.03 \pm 85.63 in female patients $(p=0.050)$. Features at disease onset are summarised in table 1. Frequency of limbs claudication was not significantly different in the two groups ( $50 \%$ vs $56.7 \%$ ), $10 \%$ of male patients had upper limbs claudication, com pared to $43.3 \%$ of female patients, $p=0.047$. Arterial hypertension was more frequent in male patients ( $70 \%$ vs $35.6 \%, p=0.044)$. Acute coronary syndrome was more frequent in male patients ( $30 \%$ vs $5.8 \%, p=0.031)$. Frequency of cardiovas cular risk was not significantly different in the two groups (40\% vs $32.7 \%)$. Coronary angiography was more frequently performed in male patients $(30 \%$ vs $2.9 \%$, $\mathrm{p}=0.009)$. At disease onset, compared to female patients, male patients coronary ( $30 \%$ vs $6.7 \%, p=0.042)$, iliac $(50 \%$ vs $15.4 \%, p=0.018)$ and femoral arteries $(40 \%$ vs $6.6 \%, p=0.008$ ) were more frequently involved. In female patients subclavian arteries were more frequently involved $(72 \%$ vs $40 \%, p=0.066)$.

\begin{tabular}{lccc}
\hline Signs/symptoms & $\mathbf{N}^{\circ}$ male patients (\%) & $\mathbf{N}^{\circ}$ female patients (\%) & P-value \\
\hline Constitutional symptoms & $5(50)$ & $61(58.7)$ & 0.740 \\
Arthralgias & $3(30)$ & $28(26.9)$ & 1 \\
Carotidynia & $1(10)$ & $25(24.0)$ & 0.451 \\
Syncope/vertigo & $2(20)$ & $22(21.2)$ & 1 \\
Neurological signs & $1(10)$ & $8(7.7)$ & 0.576 \\
Overall limbs claudication & $5(50)$ & $59(56.7)$ & 0.746 \\
Upper limbs claudication & $1(10)$ & $45(43.3)$ & $\mathbf{0 . 0 4 7 ^ { * }}$ \\
Lower limbs claudication & $5(50)$ & $25(24.0)$ & 0.125 \\
Arterial hypertension & $7(70)$ & $37(35.6)$ & $\mathbf{0 . 0 4 4 ^ { * }}$ \\
Discrepancy in BP & $1(10)$ & $29(27.9)$ & 0.287 \\
Reduced/absent pulses & $3(30)$ & $46(44.2)$ & 0.511 \\
Vascular bruits & $4(40)$ & $32(30.8)$ & 0.723 \\
Angina abdominis & $0(0)$ & $16(15.4)$ & 0.353 \\
Chest pain & $3(30)$ & $9(8.7)$ & 0.071 \\
Acute coronary syndrome & $3(30)$ & $6(5.8)$ & $\mathbf{0 . 0 3 1 ^ { * }}$ \\
Serositis & $0(0)$ & $7(6.7)$ & 1 \\
\hline
\end{tabular}

Conclusions: Male patients with TA have more frequent involvement of the coronary arteries and of the iliac and femoral arteries. As a consequence, they suffer more frequently acute coronary syndrome and lower limbs claudication. Besides, they have more frequently arterial hypertension

\section{REFERENCES :}

[1] Numano F, et al. Takayasu arteritis. Lancet 2000.

[2] Clomarmond $\mathrm{C}$, et al. Long-Term Outcomes and Prognostic Factors of Complications in Takayasu Arteritis. Circulation 2017.

[3] Fatos O, et al. Epidemiology of Takayasu arteritis. Presse Med 2017.

Disclosure of Interest: A. Tomelleri: None declared, C. Campochiaro: None declared, S. Sartorelli: None declared, A. Cariddi: None declared, G. Cavalli: None declared, E. Baldissera: None declared, L. Dagna Grant/research support from: > The Unit has received unrestricted educational grants from Abbvie, BMS Celgene, Mundipharma, Novartis, MSD, Pfizer, Roche, and SOBI. DOI: 10.1136/annrheumdis-2018-eular.5399

\section{SAT0518 THE ROLE OF LEFLUNOMIDE IN THE TREATMENT OF GIANT CELL ARTERITIS}

A. Hocevar, R. Ješe, Ž. Rotar, M. Tomšič. Dpt. of Rheumatology, University Medical Center Ljubljana, Ljubljana, Slovenia

Background: Glucocorticoids (GC) have been the mainstay treatment in giant cell arteritis (GCA) for decades. Recently tocilizumab and abatacept have been proven to be effective alternatives to glucocortiocids. However, not all GCA patients are eligible for a biologics.

Objectives: We aimed to evaluate the role of leflunomide (LEF) as a steroid sparing agent in GCA

Methods: This prospective observational study included newly diagnosed GCA patients followed at least 48 weeks at a single secondary/tertiary rheumatology centre.

Patients were treated with GC in line with the EULAR recommendations. ${ }^{1}$ In short, patients with uncomplicated GCA initially received oral methylprednisolone (MP) 32-48 mg qd, while those with ischaemic complications or large vessel disease first received MP $250 \mathrm{mg}$ on 3 consecutive days intravenously, followed by oral MP. MP tapering was started 2-4 weeks after treatment initiation slowly to $4 \mathrm{mg}$ qd which was continued for at least 6 months. At week 12, LEF $10 \mathrm{mg}$ qd was recommended as an add-on therapy to those GCA patients without contraindications for it. The final decision to add LEF was patient dependent. Follow-up visits with predetermined clinical and laboratory tests were performed 4, 12, 24, 48, 96 and 144 weeks after diagnosis. In patients who relapsed during the MP tapering unscheduled visits were arranged and treatment was adjusted (GC dose was 